\title{
An Ecofriendly synthesis of silver nano-bioconjugates by Penicillium citrinum (MTCC9999) and its antimicrobial effect
}

\author{
Achintya Mohan Goswami ${ }^{1,2}$, Tuhin Subhra Sarkar ${ }^{1}$ and Sanjay Ghosh ${ }^{1 *}$
}

\begin{abstract}
This report provides for the first time a novel environment friendly extracellular synthesis of stable silver nanobioconjugates (SNBCs) at room temperature at pH 5.0 using Penicillium citrinum MTCC 9999 biomass. The UV-Visible spectral scan of dispersed SNBCs solution showed absorption in the region 340-450 nm due to surface plasma resonance (SPR). Typical Transmission Electron Microscopic (TEM) images showed that although two populations were present but most of them were in $20-30 \mathrm{~nm}$ range. Average zeta potential of SNBCs was $-21 \mathrm{mV}$ suggesting some biomolecules capped the nanoparticles imparting a net negative charge over it. FTIR analysis also showed that biomolecules were involved in stabilization. SNBCs showed strong antibacterial activity against both Gram positive (Bacillus subtilis) and Gram negative bacteria (Escherichia coli). SNBCs also showed strong antifungal activity as assessed against Schizosaccharomyces pombe. In the case of E. coli the minimum inhibitory concentrations (MIC) of SNBCs was $4 \mu \mathrm{g} / \mathrm{ml}$ while in B. subtilis it was $8 \mu \mathrm{g} / \mathrm{ml}$. In the case of $E$. coli the minimum bactericidal concentrations (MBC) of SNBCs was $8 \mu \mathrm{g} / \mathrm{ml}$ while in B. subtilis it was $32 \mu \mathrm{g} / \mathrm{ml}$. The SNBCs exerted its antibacterial and antifungal activity through generation of reactive oxygen species (ROS) inside the cell.
\end{abstract}

Keywords: Green synthesis, Penicillium citrinum, Transmission Electron Microscopy (TEM), Zeta potential, Fourier Transformed Infra-Red Spectroscopy (FTIR), Minimum Inhibitory Concentrations (MIC), Minimum Bactericidal Concentrations (MBC), Reactive Oxygen Species (ROS)

\section{Introduction}

The field of nanotechnology has got major advances in various aspects of technology from biosensors to medicine (Velev and Kaler 1999; Nie and Emory 1997; Gu et al. 2003; Kim et al. 2008). Various optic based analytical techniques are designed based on the surface plasma resonance (SPR) properties of silver nanomaterials (Lee and EI-Sayed 2006). There is also growing interest in biomedical applications of silver nanoparticles (Sun et al. 2005). But synthesis of nanoparticles requires harsh reducing agents (e.g. sodium borohydride, hydroxyl amine), capping agents (e.g. trioctylphosphine oxide) and organic solvents (e.g. toluene, chloroform) as well as high temperature and pressure (Xie et al. 2007). So the focus is turned on to the environmental friendly synthesis of

\footnotetext{
* Correspondence: ghoshs71@hotmail.com

'Department of Biochemistry, University of Calcutta, 35, Ballygunge Circular Road, Kolkata, West Bengal 700 019, India

Full list of author information is available at the end of the article
}

nanoparticles, the so called "Green Chemistry" (Klaus et al. 1999; Raveendran et al. 2003). Complete green synthesis of silver nanoparticles requires environmentally acceptable solvent, eco friendly reducing and capping agents. In all these respects biological approach is more convenient.

A number of biological species has been shown to produce silver nanoparticles either intracellular or cell surface based or extracellular. A study with Pseudomonas stutzeri AG259, a metal accumulating bacteria have been shown to synthesize silver nanoparticles in the periplasmic space with a size ranging from a few nanometers to $200 \mathrm{~nm}$ of different shapes and morphologies (spherical, triangular, truncated triangular) (Klaus et al. 1999). Lactobacillus strains have been shown to synthesize silver nanoparticles and these form clusters on the cell surface (Nair and Pradeep 2002). Vigneshwaran $\mathrm{N}$ et al. showed a cell-surface based synthesis of silver nanoparticles with a varying particle size 
from 4-14 nm by Aspergillus flavus (Vigneshwaran et al. 2007a). Extracellular biosynthesis of silver nanoparticles of 5-25 nm diameter by Aspergillus fumigatus and Penicillium fellutanum has been studied (Bhainsa and D’Souza 2006; Kathiresan et al. 2009). Polydisperse silver nanoparticles of $20-60 \mathrm{~nm}$ diameter are synthesized extracellularly by Alternaria alternata (Monali et al. 2009). Apart from using microorganisms as a factory of synthesizing nanomaterials, soluble starch has been used in the ecofriendly synthesis of silver nanoparticles with a size 23-35 nm (Vigneshwaran and Nachane 2006). Spent mushroom substrate (SMS) has also been used as a simple root for the synthesis of silver-protein (coreshell) nanoparticles having average size around $30 \mathrm{~nm}$ (Vigneshwaran A and Kathe 2007).

There is also increasing demand for finding antimicrobial agents due to ever increasing bacterial resistance to antibiotics and consequent development of multidrug resistance in bacteria. Recently nanoparticles have been successfully used for the delivery of therapeutic agents (Zhang et al. 2008a), in chronic disease diagnostics (Hong et al. 2008), to reduce bacterial infections in skin and burn wounds (Rai et al. 2009), to prevent bacterial colonization on medical devices and in the food and clothing industries as an antimicrobial agent (Chau et al. 2007; Vigneshwaran et al. 2007b). For centuries, silver is known for its antimicrobial activity against a diverse group of bacteria and has been used for many years as an antimicrobial substance (Castellano et al. 2007). Silver nanoparticles have been shown to have potent antibacterial, antifungal and antiviral activities. Compared with other metals, silver nanoparticles show higher toxicity to microorganisms while exhibiting lower toxicity to mammalian cells (Zhao and Stevens 1998). A large number of researches were carried out to investigate the bactericidal activity of silver nanoparticles. Silver nanoparticles interact with gram-negative bacteria in a size dependent fashion (Sukdeb et al. 2007). It has been suggested that the antibacterial activity is due to silver ions, released from metallic bulk silver or from nanoparticle (NP) surfaces, which interact with the thiol groups in bacterial proteins or interfere with DNA replication (Feng et al. 2000; Wu et al. 2009). It has also been reported that silver ions can affect the respiratory chain in bacteria (Holt and Bard 2005). On the other hand, other authors have suggested that silver nanoparticle toxicity may arise directly from physical processes caused by nano-objects, like disruption of cell membrane and penetration of NPs into the cytoplasm (Xu et al. 2004). So, the scientific debate is still open concerning the mechanism of the antibacterial effect of silver nanoparticles (Sondi and SalopekSondi 2004; Dror-Ehre et al. 2009; Zhang et al. 2008b). It was reported that silver nanoparticles stabilized with sodium dodecyl sulfate (SDS) have no antibacterial activity because the negatively charged SDS interferes with the absorption of microbes to the surface of the nanoparticles or silver ions (Cho et al. 2005). So the application of silver nanoparticles as antimicrobial agent requires appropriate coating of nanoparticle surface to avoid aggregation and to favour solubility in watery environment and attachment of nanoparticle to bacterial cell surface.

Until now, little research has been done on the antimicrobial activity of biologically produced nanosilver and its specific mode of action. The aim of this study was to examine the antimicrobial properties of biogenic silver. In the present work, we report an environment friendly procedure for synthesis of stable silver nano-bioconjugate (SNBC) and its potential application as antimicrobial agent. We prefer to use the term nano-bioconjugate because of the presence of biomolecules on the nanoparticle surface, which are used for further studies without any further chemical modification of nanoparticle surface.

\section{Materials and methods}

All chemical reagents were purchased from Sigma (St. Louis, MO, USA) and were of analytical grade. All components for growth media were purchased from BectonDickinson (Rutherford, NJ, USA).

\section{Microorganism}

Penicillium citrinum (strain number MTCC 9999) was isolated in our laboratory from soil, collected from Dhapa situated near Kolkata, West Bengal. The strain was sent for identification to the Institute of Microbial Technology (IMTECH), Chandigarh, India, a centre for microbial strain identification and maintenance. The strain was identified as Penicillium citrinum by them and it was deposited in the IMTECH strain bank. The strain was subcultured on potato dextrose agar (PDA).

\section{Biomass production}

The fungus ( $P$. citrinum MTCC 9999) was grown aerobically in liquid media containing $(\mathrm{g} / \mathrm{l}) \mathrm{KH}_{2} \mathrm{PO}_{4}$ : 7.0, $\mathrm{K}_{2} \mathrm{H}$ $\mathrm{PO}_{4}: 2.0, \mathrm{MgSO}_{4}, 7 \mathrm{H}_{2} \mathrm{O}: 0.1,\left(\mathrm{NH}_{4}\right)_{2} \mathrm{SO}_{4}: 1.0$, yeast extract: 0.6 , glucose 10.0. The conical flask containing the above sterilized media was inoculated with fungal spores and incubated at orbital shaker at $29^{\circ} \mathrm{C}$ for 84 hours at $140 \mathrm{rpm}$. Then the biomass was harvested by sieving through a plastic filter and washed several times with Milli-Q deionized water to remove any traces of media components. Biomass was placed in Mili Q water to collect the fungal cell surface biomolecule or any secretory materials which could have reducing power for the biological synthesis of nanoparticles. Typically $20 \mathrm{~g}$ biomass (fresh weight) was dispersed in 200 $\mathrm{ml}$ of deionized Milli-Q water. It was then kept for 72 hours at $25^{\circ} \mathrm{C}$ at $120 \mathrm{rpm}$ in an orbital shaker. After the incubation, cell filtrate was obtained by passing it through Whatman filter paper no1 for the synthesis of silver nano- 
bioconjugates by extracellular filtrate. Each experiment was repeated thrice using freshly grown culture of $P$. citrinum in PDA.

\section{Synthesis of silver nano-bioconjugates by extracellular filtrate}

Silver nitrate $\left(\mathrm{AgNO}_{3}\right)$ at a final concentration of $0.5 \mathrm{mM}$ was added from a higher stock of $200 \mathrm{mM}$ to the cell filtrate and agitated at $100 \mathrm{rpm}$ in dark at $25^{\circ} \mathrm{C}$. Control set (only cell filtrate) without $\mathrm{AgNO}_{3}$ was also run side by side. Another negative control containing only $0.5 \mathrm{mM} \mathrm{AgNO}_{3}$ were maintained under the same conditions. Silver nanobioconjugates were characterized by visual inspection. Sample was withdrawn at various time intervals for recording of UV-Visible spectra. UV-Visible spectra were recorded spectrophotometer (V-530) (JASCO Analytical Instruments, 28600 Mary's Court, Easton, MD 21601).

\section{Characterization of silver nano-bioconjugates}

Dynamic light scattering (DLS) analysis was performed in Zetasizer (MALVERAN Nano Series, Malvern Instruments Ltd, Enigma Business Park, Grovewood Road, Malvern, Worcestershire, UK. WR14 1XZ), to measure the hydrodynamic diameter and zeta potential of SNBCs.

\section{Transmission electron microscopic (TEM) measurement}

The samples for transmission electron microscopy (TEM) analysis were prepared by drop-casting the SNBCs solution on a carbon-coated copper TEM grid. Before casting to the grid the SNBCs solution was centrifuged at $10000 \mathrm{rpm}$ for 5 minutes and the isolated SNBCs were dispersed in $100 \mu \mathrm{l}$ double distilled water and sonicated in a bath sonicator for 15 minutes. The TEM images were recorded on a high resolution electron microscope (HRTEM: JEOL JEM 2010) operating at an accelerating voltage of $200 \mathrm{kV}$. Fast Fourier transform (FFT) images were recorded with built-in software for the FFT algorithm for image processing in HRTEM: JEOL JEM 2010 instrument.

\section{Fourier transformed infra red spectroscopy (FTIR)}

For FTIR spectrum analysis the SNBCs were centrifuged at $10,000 \mathrm{rpm}$ for 10 minutes to remove free proteins or other compounds present in the solution. The SNBCs then resuspended in double distilled water and again centrifuged. The process was repeated for three times and finally the centrifuged part containing SNBCs were redispersed in double distilled water and subjected to FTIR spectroscopy.

\section{Antimicrobial activity of silver nano-bioconjugates (SNBCs)}

Antimicrobial activities of SNBCs were assayed by cupplate method. Antimicrobial activity was assayed against following Gram positive bacteria Bacillus subtilis ATCC 6633, and Gram negative bacteria Escherichia coli ATCC
8739 and fungus Schizosaccharomyces pombe ATCC 24843. Zone of inhibition was determined by measuring the diameter of bacterial clearance after 24 hour. Minimum inhibitory concentrations (MIC) and minimal bactericidal concentration (MBC) of the SNBCs were determined following the guidelines of National Committee for Clinical Laboratory Standards (NCCLS, Approved standards M7-A4 1997). Colony-forming unit (CFU) is an estimate of viable bacterial and fungal (yeast) growth measurement. The Spread Plate technique was used to determine the CFU. Bacterial suspensions were diluted in sterile Muller Hington Broth (MHB) to obtain a final inoculum of $10^{6} \mathrm{CFU} / \mathrm{ml}$. The concentrations of SNBCs tested were $1,2,4,8,16,32,64 \mu \mathrm{g} / \mathrm{ml}$. The samples were then incubated at $37^{\circ} \mathrm{C}$ at $140 \mathrm{rpm}$ for 24 hours. We have also used a control set where $P$. citrinum biomass was placed in Mili-Q water under similar experimental condition like the silver nanobioconjugate production. Minimum inhibitory concentration was determined using the control fungual ell exudates, control $0.5 \mathrm{mM}$ silver nitrate as well as the silver nanobioconjugates.

After incubation, minimum inhibitory concentrations (MIC) were read visually; all samples were plated to nutrient agar and incubated. The minimal bactericidal concentration $(\mathrm{MBC})$ was defined as a $99.9 \%$ reduction in CFU from the starting inoculum after $24 \mathrm{~h}$ incubation interval. The minimal fungicidal concentration (MFC) was defined as a $99.9 \%$ reduction in CFU from the starting inoculum after $24 \mathrm{~h}$ incubation interval. Fungal strains of $S$. pombe were grown up in YES medium $(0.5 \%$ yeast extract, $3 \%$ dextrose with proper supplements) at $32^{\circ} \mathrm{C}$.

\section{Fluorescence imaging of reactive oxygen species (ROS) production}

Radical production was quantified by the addition of the non-fluorescent precursor molecule $2^{\prime}, 7^{\prime}$ dichlorodihydrofluorescein diacetate (DCFDA). In the presence of ROS, DCFDA is oxidized to a fluorescent molecule. Bacterial cells were grown in MHB up to 0.24 O.D. at $590 \mathrm{~nm}$. Fungal strains of $S$. pombe were grown up in YES media up to $0.4 \mathrm{OD}$ at $590 \mathrm{~nm}$. The cells were then centrifuged at $5000 \mathrm{rpm}$ for 5 minutes and cell pellet is collected and dispersed in $50 \mathrm{mM}$ potassium phosphate buffer. And cells were washed to remove media. The cells were then again re-dispersed in $50 \mathrm{mM}$ potassium phosphate buffer at a final cell O.D. of 0.5 at $600 \mathrm{~nm}$. The cells were then treated with SNBCs at a final concentration of $40 \mu \mathrm{g} / \mathrm{ml}$ for 1 hour and 2 hour. After treatment DCFDA was added to the cells at a final concentration of $10 \mu \mathrm{M}$.

\section{Results}

Extracellular filtrate ( $\mathrm{pH}$ 5.0) collected from P. citrinum was able to reduce silver nitrate $(0.5 \mathrm{mM})$ to form silver nano-bioconjugates (SNBCs) resulting in the appearance 


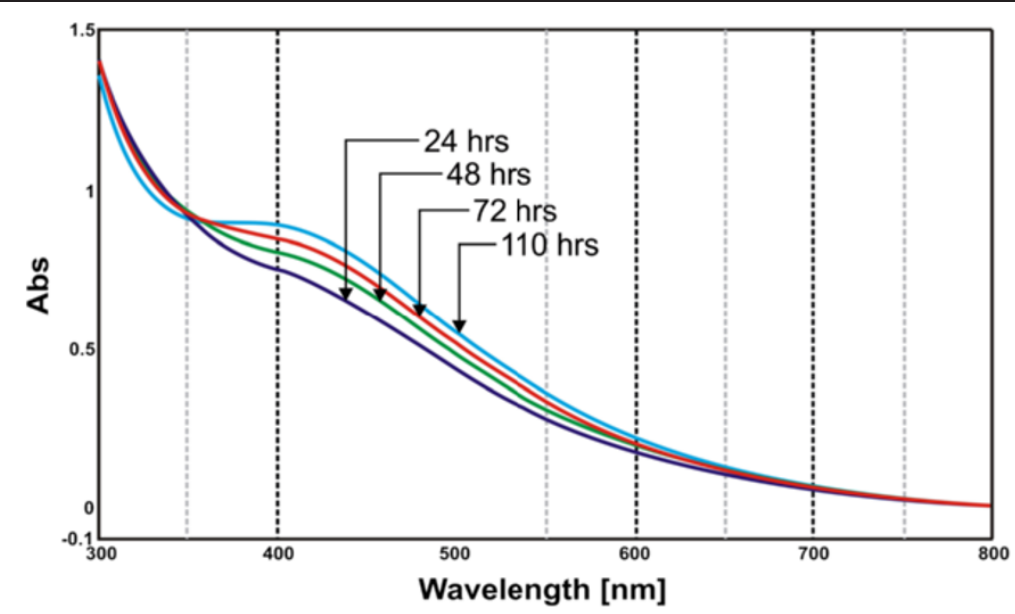

Figure 1 UV-visible spectral scan of SNBCs by bio-reduction of silver nitrate in aqueous solution were recorded at various time points viz. 24 hours, 48 hours, 72 hours and 110 hours in Jasco UV-Visible spectrophotometer (V-530) operated at a resolution of $1 \mathrm{~nm}$ in absorption mode.

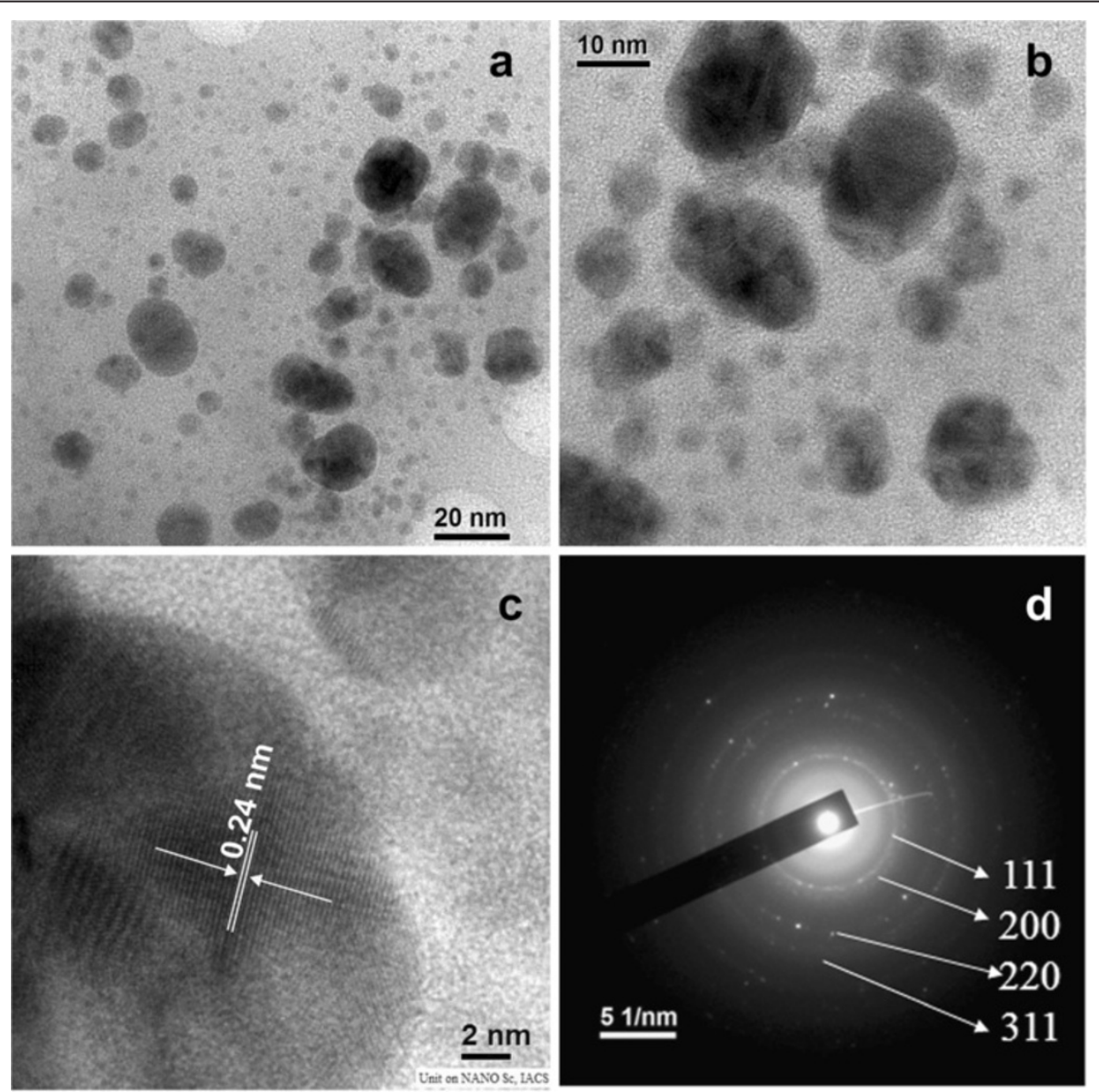

Figure 2 Characterization of SNBCs by TEM. (a) Typical TEM image of SNBCs. (b) A magnified TEM image. (c) HRTEM image of SNBCs. (d) SAED pattern of SNBCS which were indexed according to (111), (200), (220), and (311) reflections of fcc silver on the basis of their $d$-spacings of $2.47 \mathrm{~A}^{0}, 2.13 \mathrm{~A}^{0}, 1.49 \mathrm{~A}^{0}$, and $1.27 \mathrm{~A}^{0}$. 


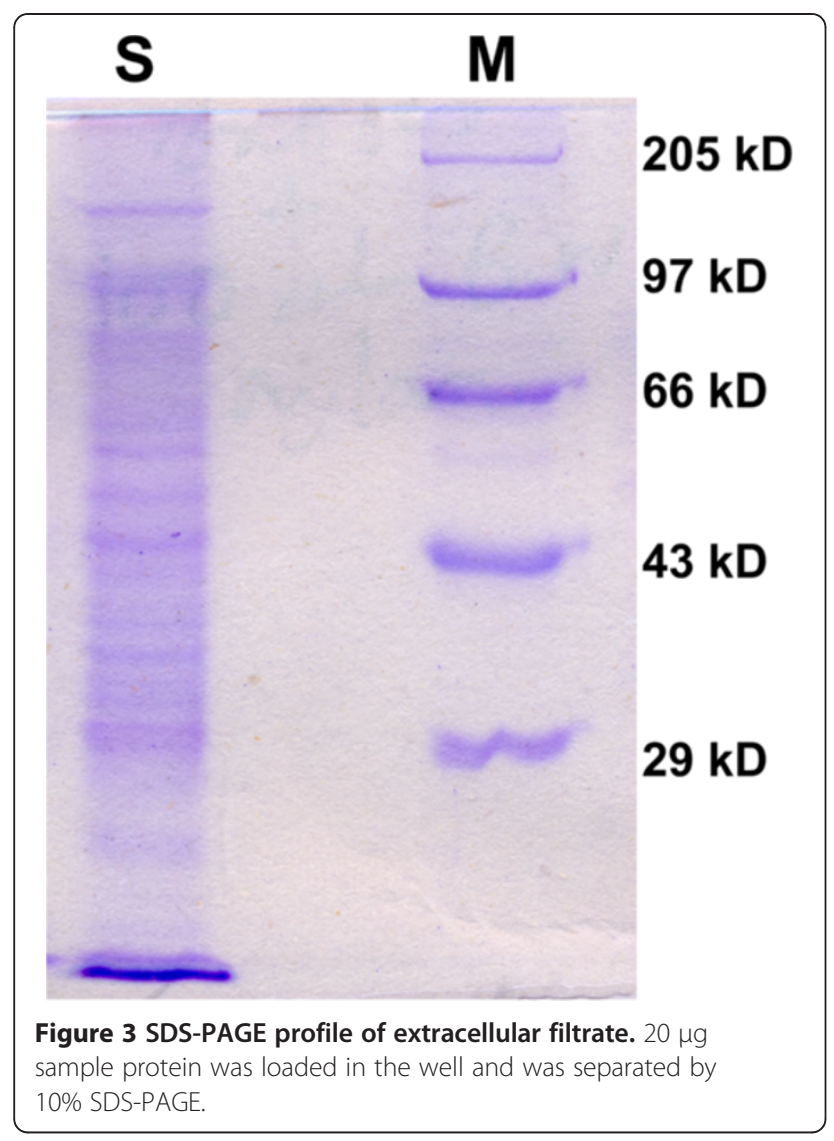

of the brown color indicating the presence of colloidal silver particles in SNBCs (Burda et al. 2005). However, no change in colour was observed in control sets (Additional file 1 Online Resource 1).

A time course study was conducted to follow the synthesis of SNBCs (Figure 1) by the extracellular filtrate of $\mathrm{pH}$ 5.0. Similar study was conducted with extracellular filtrate of $\mathrm{pH}$ 3.0, $\mathrm{pH} 7.0$ and $\mathrm{pH} 9.0$ (Data not shown). All the conditions at different $\mathrm{pH}$ generated SPR signal in the region $340-450 \mathrm{~nm}$ of SNBCs by UV-visible spectroscopy. An increase in absorbance in the region 340$450 \mathrm{~nm}$ with time indicated the synthesis of SNBCs.

SNBCs were analyzed by Dynamic Light Scattering to measure hydrodynamic diameter immediately after synthesis (Additional file 2 Online Resource 2). Interestingly, SNBCs synthesized by extracellular filtrate of $\mathrm{pH} 5.0$ showed a single population whose hydrodynamic diameter was centered on approximately $20-40 \mathrm{~nm}$. As in dynamic light scattering small particles could be masked by the large particles, so the $\mathrm{Z}$ average was $76.42 \pm 6.12$ $\mathrm{nm}$. SNBCs were further analyzed by TEM to understand the architecture, size and selected area electron diffraction (SAED) pattern. A typical TEM image of SNBCs (Figure 2a, $2 \mathrm{~b})$ revealed the presence of maximum number of spherical SNBCs. The average diameter of 281 particles measured in TEM was $9.46 \pm 6.45 \mathrm{~nm}$. A high resolution TEM
(HRTEM) image of SNBCs synthesized at $\mathrm{pH} 5.0$ (Figure 2c) showed the well resolved interference fringe patterns separated by $0.24 \mathrm{~nm}$ which corresponded well to the spacing between (111) plane of $f c c$ silver crystal (JCPDS. No.01-087-0597). The patterns of SAED (Figure 2d) were indexed according to (111), (200), (220), and (311) reflections of $f c c$ silver crystal on the basis of their $d$-spacings of $2.47 \mathrm{~A}^{\circ}, 2.13 \mathrm{~A}^{\circ}, 1.49 \mathrm{~A}^{\circ}$, and $1.27 \mathrm{~A}^{\circ}$. The TEM, HRTEM and SAED pattern of SNBCs synthesized at $\mathrm{pH} 3.0, \mathrm{pH} 7.0$ and $\mathrm{pH} 9.0$ showed similar pattern as obtained in SNBCs synthesized at pH 5.0 (Additional file 3 Online Resource 3) However, there were distinct differences in their hydrodynamic diameter and zeta potential values.

The zeta potential of SNBCs was measured to know their colloidal stability and the nature of the charge carried in their surface. The average zeta potential of SNBCs, synthesized by extracellular filtrate of $\mathrm{pH}$ 5.0, was approximately $-21 \mathrm{mV}$ (Additional file 4 Online Resource 4). In spite of this zeta potential value the SNBCs were well stabilized at room temperature as determined by measuring the hydrodynamic diameter by DLS, 30 days after synthesis, with little or no aggregation at all.

To investigate the reason for stabilization up to 30 days after synthesis of SNBCs, it was further characterized in SDS-PAGE (Figure 3) to find if any proteins were present on the surface of the nanoparticles or not. SDS-PAGE profile of the extracellular filtrate clearly shows the presence of proteins in the filtrate. SNBCs were then analyzed by FT-IR spectroscopy in solid mode to provide further evidence (Figure 4) and it showed both amide I $\left(1642.06 \mathrm{~cm}^{-1}\right)$ and amide II $\left(1541.04 \mathrm{~cm}^{-1}\right)$ stretching frequencies present in SNBCs (Caruso et al. 1998).

We have tested the antibacterial activity of SNBCs against $E$. coli and B. subtilis and antifungal activity against S. pombe. Antimicrobial activity of SNBCs at a concentration of $200 \mu \mathrm{g} / \mathrm{ml}$ was determined by agar diffusion assay (Additional file 5 Online Resource 5). Zone of inhibition determined for $E$. coli by measuring the diameter of bacterial clearance after 24 hour was $3.68 \pm 0.1 \mathrm{~mm}$ and that for B. subtilis was $2.81 \pm 0.2 \mathrm{~mm}$. Zone of inhibition determined for $S$. pombe by measuring the diameter of fungal clearance after 24 hour was $1.87 \pm 0.15 \mathrm{~mm}$. We have also used $0.5 \mathrm{mM}$ silver nitrate and fungal cell exudates in MilliQ water as control to assess their antimicrobial potency. It was found that silver nitrate showed antimicrobial activity like that of SNBCs. But no zone of inhibition was observed in case of fungal cell exudates in MilliQ water.

The Minimum inhibitory concentrations (MIC) was defined as the lowest silver concentration, which showed no increase in optical density (OD), i.e. no bacterial or fungal growth during 24 hours of inoculation. MIC of SNBCs against $E$. coli, B. subtilis and S. pombe were represented in 


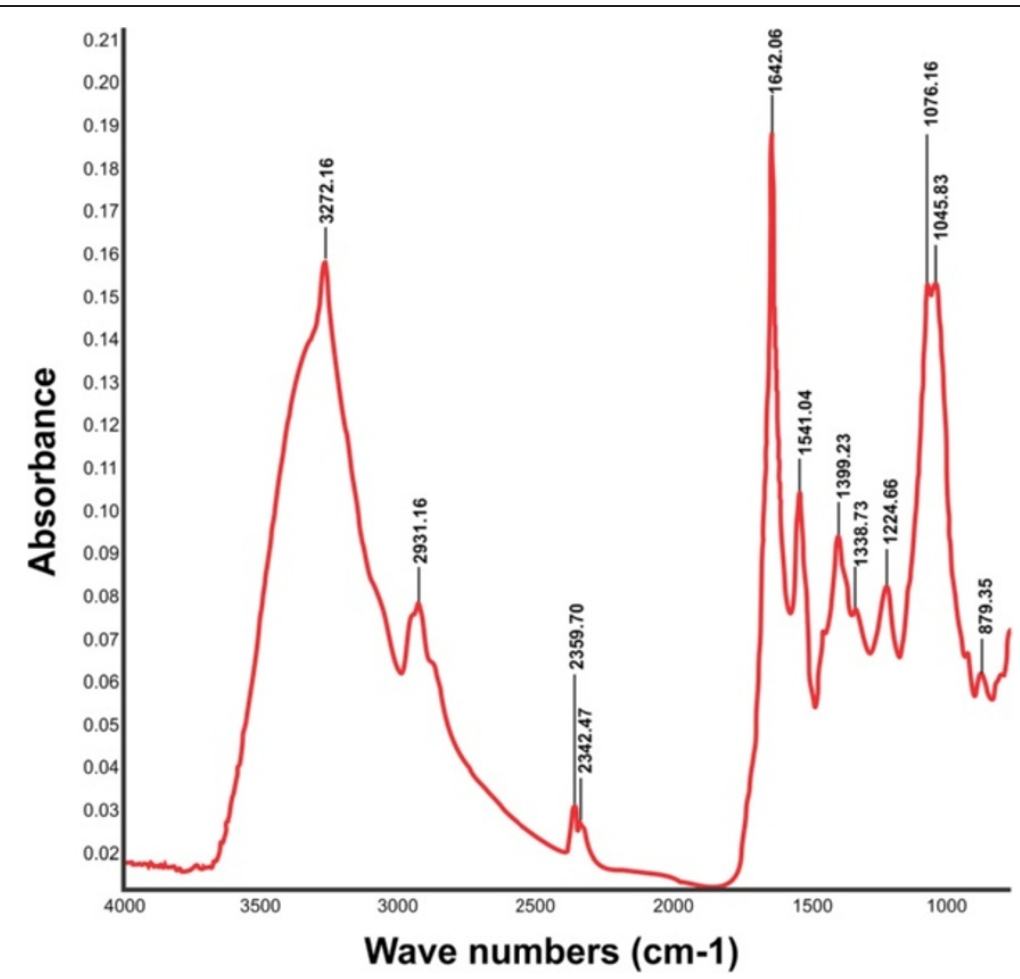

Figure 4 FT-IR spectra of SNBCs. SNBCs were centrifuged at 10,000 rpm for 10 minutes to remove free proteins or other compounds present in the solution. The SNBCs then resuspended in double distilled water and again centrifuged. The process was repeated for three times and finally the centrifuged part containg SNBCs were redispersed in double distilled water and subjected to FTIR spectroscopy.

Additional file 6 Online Resource 6. In the case of Gram negative bacteria $E$. coli the MIC was $4 \mu \mathrm{g} / \mathrm{ml}$ while for Gram positive bacteria B. subtilis the MIC was $8 \mu \mathrm{g} / \mathrm{ml}$ and for the $S$. pombe the value was $8 \mu \mathrm{g} / \mathrm{ml}$. The minimal concentration of SNBCs which gave rise to plates without bacterial colonies was considered as the minimal bactericidal concentration (MBC). The MBC (or MFC) of SNBCs in growth medium was $8 \mu \mathrm{g} / \mathrm{ml}$ for $E$. coli and $32 \mu \mathrm{g} / \mathrm{ml}$ for $B$. subtilis and $16 \mu \mathrm{g} / \mathrm{ml}$ for S. pombe (Additional file 6 Online Resource 6).

To investigate the mechanism of action of SNBCs towards its antimicrobial activity, we found reactive oxygen species (ROS) generation inside both bacterial and fungal cells (Figure 5). E. coli cells (0.24 O.D. at $590 \mathrm{~nm}$ ) when treated with SNBCs at a final concentration of $40 \mu \mathrm{g} / \mathrm{ml}$ showed generation of ROS as studied by fluorescence microscopy. The control set showed no ROS generation. Treatment of B. subtilis (0.24 O.D. at $590 \mathrm{~nm})$ with SNBCs at a final concentration of $40 \mu \mathrm{g} / \mathrm{ml}$ showed generation of ROS as studied by fluorescence microscopy. The control set showed no ROS generation. S. pombe $(0.4 \mathrm{OD}$ at $590 \mathrm{~nm})$ when treated with SNBCs at a final concentration of $40 \mu \mathrm{g} / \mathrm{ml}$ also showed generation of ROS as studied by fluorescence microscopy. The control set showed no ROS generation.

\section{Discussion}

In our study SNBCs formed a single population as revealed by DLS analysis in the size range of $20-40 \mathrm{~nm}$. The physical nature of SNBCs as revealed by TEM images that most of the SNBCs were quite spherical in shape with their average diameter of $9.46 \pm 6.45 \mathrm{~nm}$. It is true that quantification of $\mathrm{Ag}(0)$ is not accurate from the absorbance value of the SPR signal of the SNBCs. Concentration calculation from the molar extinction coefficient value depends on the size of the molecule in a homogeneous population. Although microbial synthesized SNBCs contain a heterogeneous population of different size, still we tried to quantitate the $\mathrm{Ag}(0)$ content of SNBCs with an average diameter $9.46 \mathrm{~nm}$ and $15.91 \mathrm{~nm}$ using the extinction coefficient value of $4.16 \times 10^{9} \mathrm{M}^{-1} \mathrm{~cm}^{-1}$. (Yguerabide and Yguerabide 1998). It is observed that $15.69 \times 10^{-2} \mathrm{nM}$ $\mathrm{Ag}(0)$ is produced from $0.5 \mathrm{mM} \mathrm{AgNO}$.

Average zeta potential of SNBCs measured to be $-21 \mathrm{mV}$ suggesting that some biomolecules capped the surface imparting a net negative charge over it. It could be well assumed that the biomolecules present in extracellular filtrate not only involved in the synthesis but providing the surface coating of silver nanoparticles making them well stable. SDS-PAGE profile of the extracellular filtrate clearly showed the presence of proteins in the filtrate. It is 


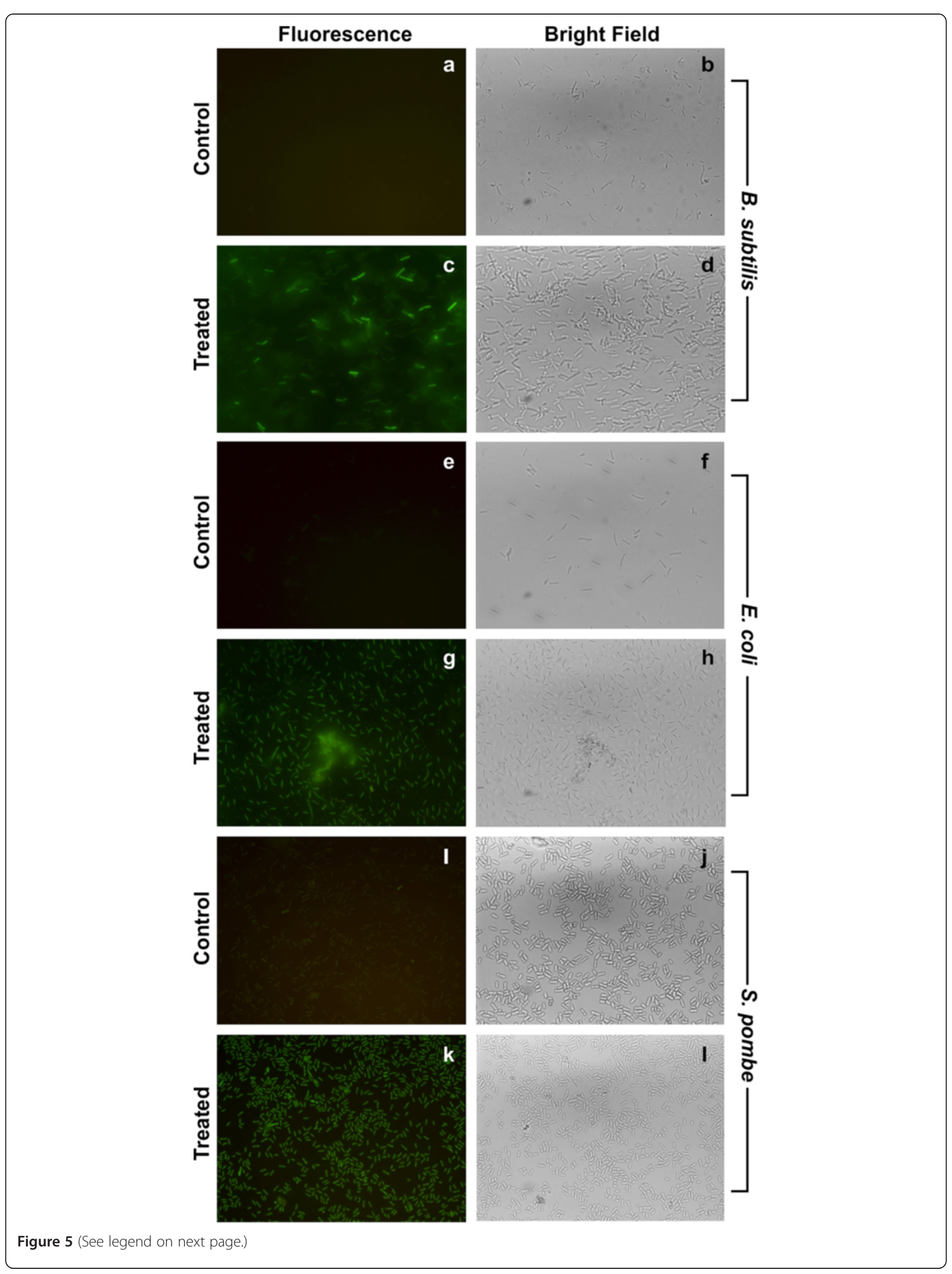


conceivable that the biomolecules present in extracellular filtrate are not only involved in the synthesis but also providing the surface coating of silver nanoparticles making them well stable. So it is possible that some of these proteins and other biomolecules such as chitin, lipid etc. may be present on SNBCs and help to stabilize the SNBCs. It has been shown that silver nanoparticles have affinity for free amine groups or SH-group of cysteine residues of the proteins or through electrostatic attraction of negatively charged carboxylate groups (Gole et al. 2001). FT-IR analysis of SNBCs again confirmed the presence of biomolecules in the SNBCs.

The ever growing bacterial resistance to antimicrobial agents poses a serious problem in the treatment of infectious diseases as well as in epidemiological practice (Neu 1992). The surface structures of silver nanoparticles are found to be become important in mediating its antimicrobial activity (Cho et al. 2005). Thus we wanted to know the antimicrobial property of SNBCs which have outer coating of biomolecules. In this study antibacterial activity of SNBCs was observed against E. coli and B. subtilis and antifungal activity against $S$. pombe. The zone of inhibition as determined by agar diffusion method for $E$. coli was larger than that for B. subtilis. This was most probably due to variation in cell wall composition between gram negative $E$. coli and gram positive B. subtilis. It was evident from Additional file 6 Online Resource 6 that both MIC and $\mathrm{MBC}$ values were higher for $B$. subtilis than E. coli. This may be due to the fact that cell wall structure in $B$. subtilis provided resistance against the diffusion and action of SNBCs.

Generation of reactive oxygen species (ROS) inside both bacterial and fungal cells provides the mechanism of action of SNBCs towards its antimicrobial activity. It is known that majority of nanomaterials such as zinc oxide, carbon nanotubes, and silicon dioxide exert their toxic effects through oxidative stress (Yang et al. 2008). It is believed that nanoparticle toxicity is multifactorial, where size, shape, surface functionalization and potential to release the corresponding metal ions could play pivotal roles. ROS generation in the presence of SNBCs could be explained by metabolic disturbances as well as other toxicological outcomes. It is also possible that surface oxidation of silver nanoparticle liberates $\mathrm{Ag}^{+}$ions that could amplify the toxicity. Reactions between $\mathrm{H}_{2} \mathrm{O}_{2}$ and silver nanoparticle may be responsible for release of $\mathrm{Ag}^{+}$ions in vivo (Kumar 2006).
A possible chemical reaction involves

$$
2 \mathrm{Ag}+\mathrm{H}_{2} \mathrm{O}_{2}+2 \mathrm{H}^{+} \longrightarrow 2 \mathrm{Ag}^{+}+2 \mathrm{H}_{2} \mathrm{O} \quad \mathrm{E}^{0}=0.17 \mathrm{~V}
$$

Thus silver ions may be released from SNBCs upon its reaction with $\mathrm{H}_{2} \mathrm{O}_{2}$ which was produced by the action of SNBCs on E. coli, B. subtilis and S. pombe. Proteomic analysis of the effect of silver ions $\left(\mathrm{Ag}^{+}\right)$on expression of various proteins in E. coli showed a reduction in expression of ribosomal subunit S2, succinyl coenzyme (CoA) synthetase, and maltose transporter (Yamanaka et al. 2005). It was quite obvious that the reduction in expression of ribosomal subunit S2 impairs the synthesis of proteins, whereas reduction in synthesis of succinyl CoA synthetase and maltose transporter causes suppression of intracellular production of ATP. All these factors were involved in killing mechanism of SNBCs.

In conclusion, the focus of this manuscript was on the antibacterial mechanism of stable silver nanobioconjugate, synthesized by an eco-friendly process. It was found that SNBCs exerted antimicrobial activity towards both Gram positive and Gram negative bacteria and fungus. The MIC and $M B C$ values were higher for Gram positive bacteria (i.e. B. subtilis) than Gram negative bacteria (i.e. E. coli). We found generation of ROS as mediator of antimicrobial activity of SNBCs.

\section{Additional files}

Additional file 1: Online resource 1. Extracellular synthesis of Silver nano-bioconjugate at $\mathrm{pH}$ 5.0. (a) Picture of extracellular filtrate. (b) Picture of silver nano-bioconjugate.

Additional file 2: Online resource 2. Measurement of hydrodynamic diameter of SNBCs by Dynamic Light Scattering.

Additional file 3: Online resource 3. The TEM, HRTEM and SAED pattern of SNBCs synthesized at pH 3.0, pH 7.0 and pH 9.0. TEM image of SNBC synthesized by extracellular fungal extract of $\mathrm{pH} 3.0(\mathbf{a}) ; \mathrm{pH} 7.0$ (d) and $\mathrm{pH} 9.0(\mathbf{g})$. SAED pattern of SNBCs of $\mathrm{pH} 3.0(\mathbf{b}), \mathrm{pH} 7.0(\mathbf{e})$ and pH 9.0 (h) which were indexed according to (111), (200), (220), and (311) reflections of fcc silver crystal on the basis of their $d$-spacing. HRTEM image of SNBCs synthesized by extracellular fungal extract of pH 3.0 (c); $\mathrm{pH} 7.0$ (f) and $\mathrm{pH} 9.0$ (i).

Additional file 4: Online resource 4. Zeta potential of SNBCs.

Additional file 5: Online resource 5. Antimicrobial activity assay using agar diffusion. Determination of antimicrobial activity of SNBCs, silver nitrate $(\mathrm{AgNO})$ and fungal cell exudate in agar diffusion assay against $E$. coli and B. subtilis and S. pombe. The data was represented as mean \pm SD.

Additional file 6: Online resource 6. Minimum inhibitory

concentrations, minimal bactericidal concentrations and minimal fungicidal concentrations of SNBCs. Minimum inhibitory concentrations (MIC) of SNBCs were determined against E.coli, B. subtilis and S. pombe. 
Minimal Bactericidal Concentrations (MBC) of SNBCs were determined against E.coli and B. subtilis and Minimal Fungicidal Concentrations (MFC) against $S$. pombe.

\section{Competing interests}

The authors declare that they have no competing interests.

\section{Acknowledgement}

This work is supported by Centre for Research in Nano Science and Nanotechnology (CRNN), University of Calcutta. The authors would like to thank Shantiswarup Sinha and Prof. Anjan Dasgupta for assistance with the FTIR measurements. The authors would like to acknowledge DST-FIST, UGCCAS programme, DBT-IPLS programme Govt. of India, Indian Association for Cultivation of Science (I.A.C.S.), Jadavpur for equipment and infrastructural support.

\section{Author details}

'Department of Biochemistry, University of Calcutta, 35, Ballygunge Circular Road, Kolkata, West Bengal 700 019, India. ${ }^{2}$ Department of Physiology, Krishnagar Government College, Krishnagar, Nadia, West Bengal PIN-74101, India.

Received: 11 February 2013 Accepted: 13 February 2013

Published: 23 February 2013

\section{References}

Bhainsa KC, D'Souza SF (2006) Extracellular biosynthesis of silver nanoparticles using the fungus Aspergillus fumigatus. Colloids and Surface B Biointerfaces 47:160-164

Burda C, Chen X, Narayanan R, El-Sayed MA (2005) Chemistry and properties of nanocrystals of different shapes. Chem Rev 105:1025-1102

Caruso F, Furlong DN, Ariga K, Ichinose I, Kunitake T (1998) Characterization of Polyelectrolyte-Protein Multilayer Films by Atomic Force Microscopy, Scanning Electron Microscopy, and Fourier Transform Infrared ReflectionAbsorption Spectroscopy. Langmuir 14:4559-4565

Castellano JJ, Shafii SM, Ko F, Donate G, Wright TE, Mannari RJ, Pyne WG, Smith DJ, Robson MC (2007) Comparative evaluation of silver-containing antimicrobial dressings and drugs. Int Wound J 4:114-122

Chau CF, Wu SH, Yen GC (2007) The development of regulations for food nanotechnology. Trends Food Sci Technol 18:269-280

Cho KH, Park JE, Osaka T, Park SG (2005) The study of antimicrobial activity and preservative effects of nanosilver ingredient. Electrochim Acta 51:956-960

Dror-Ehre A, Mamane H, Belenkova T, Markovich G, Adin A (2009) Silver nanoparticle- $E$. coli colloidal interaction in water and effect on E-coli survival. J Colloid Interface Sci 339:521-526

Feng QL, Wu J, Chen GQ, Cui FZ, Kim TN, Kim JO (2000) A mechanistic study of the antibacterial effect of silver ions on Escherichia coli and Staphylococcus aureus. J Biomed Mater Res 52:662-668

Gole A, Dash C, Ramakrishnan V, Sainkar SR, Mandale AB, Rao M, Sastry M (2001) Pepsin-gold conjugates: preparation, characterization, and enzymatic activity. Langmuir 17:1674-1679

Gu H, Ho PL, Tong E, Wang L, Xu B (2003) Presenting vancomycin on nanoparticles to enhance antimicrobial activities. Nano Lett 3:1261-1263

Holt KB, Bard AJ (2005) Interaction of silver (I) ions with the respiratory chain of Escherichia coli: an electrochemical and scanning electrochemical microscopy study of the antimicrobial mechanism of micromolar $\mathrm{Ag}^{+}$. Biochemistry 44:13214-13223

Hong B, Kai J, Ren Y, Han J, Zou Z, Ahn CH, Kang KA (2008) Highly sensitive rapid, reliable, and automatic cardiovascular disease diagnosis with nanoparticle fluorescence enhancer and MEMS. Adv Exp Med Biol 614:265-273

Kathiresan K, Manivannan S, Nabeel MA, Dhivya B (2009) Studies on silver nanoparticles synthesized by a marine fungus, Penicillium fellutanum isolated from coastal mangrove sediment. Colloids Surf B Biointerfaces 71:133-137

Kim KJ, Sung WS, Moon SK, Choi JS, Kim JG, Lee DG (2008) Antifungal effect of silver nanoparticles on dermatophytes. J Microbiol Biotechnol 18:1482-1484

Klaus T, Joerger R, Osson E, Granqvist CG (1999) Silver based crystalline nanoparticles, Microbially fabricated. Proc Natl Acad Sci 96:13611-13614

Kumar C (2006) Nanomaterials-toxicity, health and environmental issues. WileyVCH Verlag GmbH \& Co, Weinheim, Germany
Lee KS, El-Sayed MA (2006) Gold and silver nanoparticles in sensing and imaging: sensitivity of plasmon response to size, shape, and metal composition.J Phys Chem B 110:19220-19225

Monali G, Jayendra K, Avinash I, Aniket G, Mahendra R (2009) Fungus-mediated synthesis of silver nanoparticles and their activity against pathogenic fungi in combination with fluconazole. Nanomedicine: Nanotechnology, Biology, and Medicine 5:382-386

Nair B, Pradeep T (2002) Coalescence of nanoclusters and formation of submicron crystallites assisted by Lactobacillus Strain. Cryst Growth des 2:293-298

NCCLS, Approved standards M7-A4 (1997) Methods for dilution antimicrobial susceptibility tests for bacteria that grow aerobically. National Committee for Clinical Laboratory Standards, Wayne, PA

Neu HC (1992) The crisis in antibiotic resistance. Science 257:1064-1073

Nie S, Emory SR (1997) Probing single molecules and single nanoparticles by surface enhanced Raman scattering. Science 275:1102-1106

Rai M, Yadav A, Gade A (2009) Silver nanoparticles as a new generation of antimicrobials. Biotechnol Adv 27:76-83

Raveendran P, Fu J, Wallen SL (2003) Completely "green" synthesis and stabilization of metal nanoparticles. J Am Chem Soc 125:13940-13941

Sondi I, Salopek-Sondi B (2004) Silver nanoparticles as antimicrobial agent: a case study on E. coli as a model for Gram-negative bacteria. J Colloid Interface Sci 275:177-182

Sukdeb P, Yu Kyung T, Joon Myong S (2007) Does the antibacterial activity of silver nanoparticles depend on the shape of the nanoparticle? a study of the Gram-negative bacterium Escherichia coli. Appl Environ Microbiol 73:1712-1720

Sun RWY, Chen R, Chung NPY, Ho CM, Lin CLS, Che CM (2005) Silver nanoparticles fabricated in HEPES buffer exihibit cytoprotective activities toward HIV-1 infected cells. Chem Commun 40:5059-5061

Velev OD, Kaler EW (1999) In Situ Assembly of Colloidal Particles into Miniaturized Biosensors. Langmuir 15:3693-3698

Vigneshwaran A, Kathe AA (2007) Silver-protein (core-shell) nanoparticle production using spent mushroom substrate. Langmuir 23:7113-7117

Vigneshwaran N, Ashtaputre NM, Varadaranjan PV, Nachane RP, Paralikar KM, Balasubramanya RH (2007a) Biological synthesis of silver nanoparticles using the fungus Aspergillus flavus. Mater Lett 61:1413-1418

Vigneshwaran N, Kathe AA, Varadarajan PV, Nachane RP, Balasubramanya RH (2007b) Functional finishing of cotton fabrics using silver nanoparticles. J Nanosci Nanotechnol 7:1893-1897

Vigneshwaran N, Nachane RP (2006) A novel one-pot green synthesis of stable silver nanoparticle using soluble starch. Carbohydrate Res 341:2012-2018

Wu J, Hou SY, Ren DC, Mather PT (2009) Antimicrobial properties of nanostructured hydrogel webs containing silver. Biomacromolecules 10:2686-2693

Xie J, Lee JY, Wang DIC, Ting YP (2007) Identification of active biomolecules in the high-yield synthesis of single-crystalline gold nanoplates in algal solutions. Small 3:672-682

Xu XHN, Brownlow WJ, Kyriacou SV, Wan Q, Viola JJ (2004) Real-time probing of membrane transport in living microbial cells using single nanoparticle optics and living cell imaging. Biochem 43:10400-11043

Yamanaka M, Hara K, Kudo J (2005) Bactericidal actions of a silver ion solution on Escherichia coli, studied by energy-filtering transmission electron microscopy and proteomic analysis. Appl Environ Microbiol 71:7589-7593

Yang H, Liu C, Yang D, Zhang H, Xi Z (2008) Comparative study of cytotoxicity, oxidative stress and genotoxicity induced by four typical nanomaterials: the role of particle size, shape and composition. J Appl Toxicol 29:69-78

Yguerabide J, Yguerabide EE (1998) Light-scattering submicroscopic particles as highly fluorescent analogs and their use as tracer labels in clinical and biological applications. Ana Biochem 262:137-156

Zhang L, Gu FX, Chan JM, Wang AZ, Langer RS, Farokhzad OC (2008a) Nanoparticles in medicine: therapeutic applications and developments. Clin Pharmacol Ther 83:761-769

Zhang Y, Peng H, Huang W, Zhou Y, Yan D (2008b) Facile preparation and characterization of highly antimicrobial colloid Ag or Au nanoparticles. J Colloid Interface Sci 325:371-376

Zhao G, Stevens SE Jr (1998) Multiple parameters for the comprehensive evaluation of the susceptibility of Escherichia coli to the silver ion. BioMetals 11:27-32

doi:10.1186/2191-0855-3-16

Cite this article as: Goswami et al:: An Ecofriendly synthesis of silver nano-bioconjugates by Penicillium citrinum (MTCC9999) and its antimicrobial effect. AMB Express 2013 3:16. 